\title{
A MULTI-CHANNEL CONTROLLER FOR A SCG IN A MULTI-MACHINE POWER SYSTEM
}

\author{
G. A. MORSY \\ Department of Electrical Engineering, Faculty of Engineering, \\ Minoufiya University, Shebin-El-Kom, Egypt.
}

\begin{abstract}
This paper describes the development of a multi-channel control scheme to enhance the performance of a superconducting generating (SCG) unit operated in a multi-machine power system. The proposed control scheme is designed and implemented in the governor control loop of the SCG to overcome problems resulting from the low inherent damping nature of the SCG, which has structure different from those of the conventional synchronous machines. The design of the controller is based on developing an equivalent model of the SCG, which includes the effects of interactions with other generators. This simplifies the design procedures and produce control structure that use control signals measured from local generators only. The effectiveness of the controller is demonstrated by a detailed digital computer simulation of a multi-machine power system. The system consists of a 12-bus, 4-generators one of them is a $2000 \mathrm{MW}$ SCG. The performance of the proposed controller is obtained and assessed in comparison with others, obtained using controllers designed by conventional tecliniques. It has been clearly demonstrated that the new controller improves the performance of the SCG, on which the controller is installed, as well as of all other generators in the network.

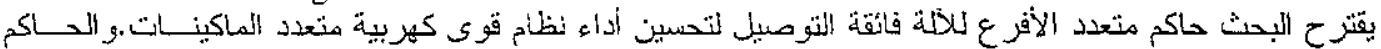

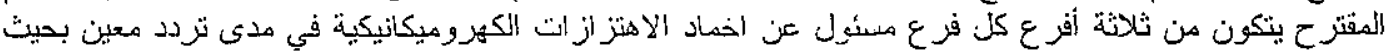

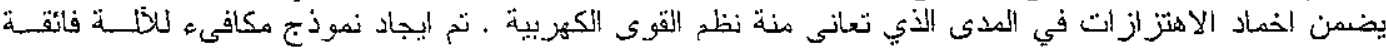

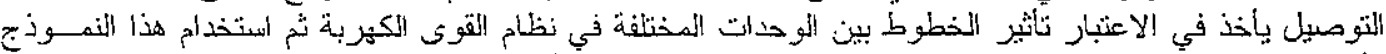

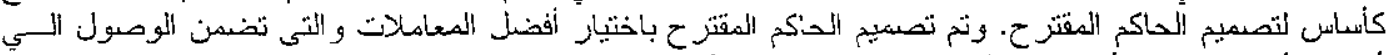

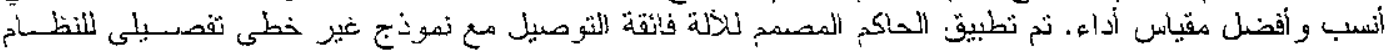

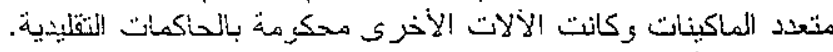

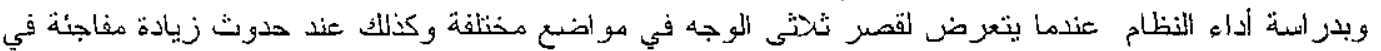

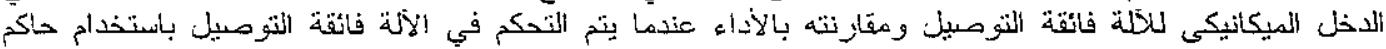

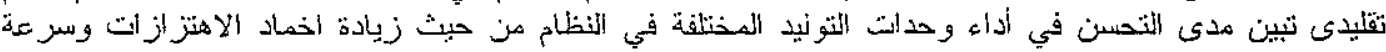
عودة المتغير ات المي قيمها المبدئية.
\end{abstract}

Keywords: Multimachine power system, Superconducting generator, Multi-channel controller

\section{1-INTRODUCTION}

The electric power grid is complex in nature with many operational levels made up of a wide range of energy sources with many interaction points (operators, power consumers and producers, and several layers including power plants, control centers, transmission and distribution networks)[1]. Due to the increasing size and complexity of these power systems, they often operate with a lower stability margin [2]. This renders a poor performance of the generators when the system is subjected to a disturbance. In addition to the continous growing demand of electric power and in the network size, there has been a trend to up grade the rating of generators. However, the physical limitation on conventional generator design may not satisfy these requirements. Subsequently, SCG are expected to be a good alternative to replace conventional generators in the future. The new machine has several advantages over conventional generators, including higher efficiency, lower synchronous reactance, reduced size and weight and the future possibility of generating at transmission voltages [3]. The new machine is also expected to exceed the rating limits of conventional machines design [4]. At present, unit ratings of 300 to $1000 \mathrm{MVA}$ are considered to be a practical size as a first unit to be synchronized into power systems $[5,6]$.

The superconducting machine is characterized by its low p.u. reactance which certainly improves stability limits. However, the new machine has a low inherent damping characteristics which makes the machine oscillate with very poor damping when subjected to 
disturbances. Therefore, stability enhancement is becoming more important for reliable operation of electric power systems.

Large interconnected power systems face the problem of poorly damped modes, in the range of 0.02 to $2.5 \mathrm{~Hz}$ [7]. These oscillations result when the rotors of machines oscillate with respect to each other using the transmission lines between them to exchange energy [8]. PSSs are used to. damp these low frequency oscillations for conventional synchronous generating units. However, Superconducting generators have a complex structure and require materials different from those normally used in conventional machines. The very long field winding time constant of that new machine makes the achievement of acceptable dynamic performance very difficult using excitation control. Therefore, it is necessary to consider only the governor control loop. Various control schemes were developed to enhance the performance of that complex structure machine [9-13].

This paper presents the design and implementation of a multi-channel control scheme in the governor control loop of a SCG operating in a multi-machine enveronment. To achieve a higher level of accuracy in the predicted results and draw a general conclusion from the results, detailed representation were made for all system components including generators. Moreover, the machines included are of different sizes and types with fast and slow acting excitation systems. The results obtained illustrate the effectiveness of the proposed controller in comparison with conventional controllers and phase advance network to enhance the overall system performance under severe disturbances.'

\section{2- STUDIED SYSTEM}

A four machine 12-bus power system without infinite bus is considered as shown in Fig. 1. This is a typical power system in which the generating units are connected to four load areas through transmission network. The transmission lines are represented using the $\pi$-method. A 590 MVA thermal unit is connected to bus 1; a 1300 MVA nuclear unit is comected to bus2; a 2000 MVA superconducting unit is connected to bus 3 and a 615 MVA hydroelectric unit to bus 4. A load flow study for a full load state of the system is shown in Fig. 1. Parameters of generators and transmission lines are given in the Appendix.

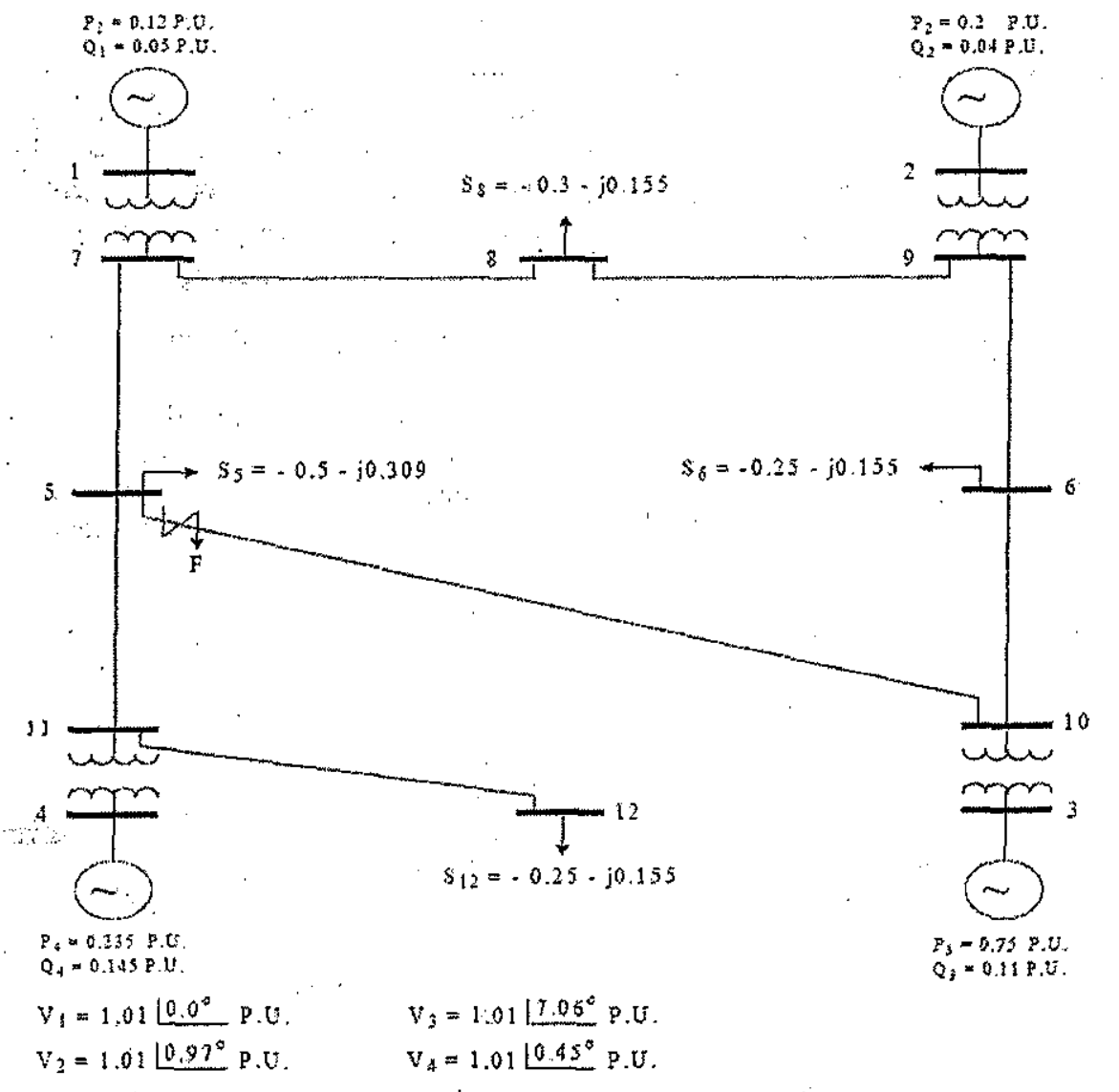

Fig. 1 Studied System 


\section{3- MULTI-MACHINE SYSTEM MODEL}

\section{3-1 Generators}

For an accurate pridiction of the system performance and to assess the effects of system controllers, a detailed representation for all generators and their control systems was made. A seventh order nonlinear mathematical model based on Park's d-q axes representation [4], is used to represent each conventional machine. However, a nineth order nonlinear model is used to represent the SCG. This is due to that each of the rotor double screens is represented by one coil, of fixed parameters, on each axis $[9,10]$.

\section{3-2 Conventional Control Systems}

All conventional generators are equipped with exciters, AVRs and PSSs. The block diagram of the typical excitation system used is shown in Fig.2, and the appropriate parameters are given in the Appendix. To reduce the order of the system, it is assumed that the mechanical input to each conventional generator is fixed. However, due to the different construction of the superconducting generator and the extremely long field winding time constant, the governor control loop is considered as the avilable control loop. A three-stage steam turbine with reheat and a fast acting electro-hydraulic governor are connected to that machine $[4,10]$. Turbine and governor state space equations are given in the Appendix. The governor valves are actuated by a speed error signal through a feedback loop incorporating a phase advance network. The incorporated phase advance network has the following transfer function [9]:

$$
\mathrm{G}_{\text {plad }}(\mathrm{s})=\mathrm{K}_{\mathrm{phad}}\left[1+\mathrm{s} \mathrm{T}_{1} / 1+s \mathrm{~T}_{2}\right]
$$

where, $K_{\text {plad }}=0.1, T_{1}=0.5 \mathrm{sec}$ and $T_{2}=0.01 \mathrm{sec}$. $\left(T_{1} / T_{2}=50\right.$ were recommended for best performance).

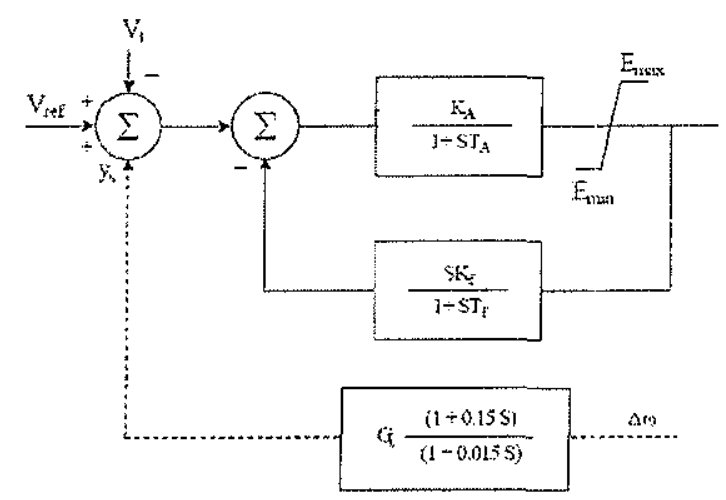

Fig.2.Conventional machines excitation system

\section{4- MULTI-CHANNEL CONTROLLER 4-1 Design Philosophy}

In this section, the control of the SCG is improved through replacing the phase advance network by a multi-channel controller. The multi-channel controller is a high order controller, whose time constants are chosen in order to damp out specific ranges of modes $[14,15]$. It consists of three frequency bands each of them contains two multistage control channels. Considering the general definition given in [15] and the schematic diagram shown in Fig.3, the controller can be defined as follows [16]:

$$
\mathrm{H}(\mathrm{s})=\mathrm{K}_{\mathrm{t}}\left[\mathrm{K}_{\mathrm{LF}} \mathrm{H}_{\mathrm{LF}}(\mathrm{s})+\mathrm{K}_{\mathrm{IF}} \mathrm{H}_{\mathrm{IF}}(\mathrm{s})+\mathrm{K}_{\mathrm{hF}} \mathrm{H}_{\mathrm{hF}}(\mathrm{s})\right]
$$

where, $K_{t}$ is the controller overall gain. Subscripts $\mathrm{LF}, \mathrm{IF}, \mathrm{hF}$ stand for low, intermediate and high frequency, respectively.

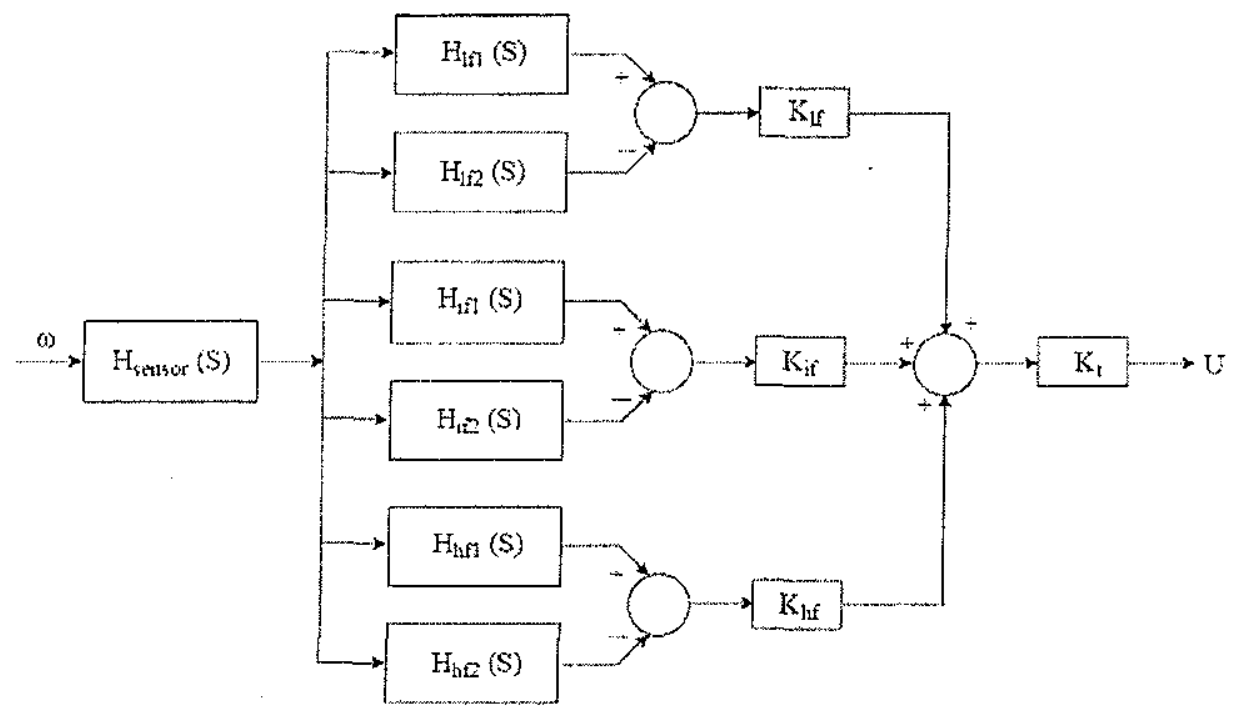

Fig.3 Schematic diagram of a multi-channel controller 
Each stage in the control channels is tuned to damp a specific frequency band. For each frequency band:

$\mathrm{H}_{\mathrm{JF}}(\mathrm{s})=\mathrm{H}_{\mathrm{JF} 1}(\mathrm{~s})-\mathrm{H}_{\mathrm{JF}}(\mathrm{s}) \quad, \mathrm{J}=\mathrm{L}, \mathrm{I}, \mathrm{h}$

Previous extensive investigation revaled that for the SCG time constants ratio is 50 for each control channel. Also, only one stage for each frequency band channel was found enough. Therefore, each controller stage takes the form:

$\mathrm{H}_{\mathrm{JFi}}(\mathrm{s})=1+\mathrm{sT}_{\mathrm{JF} 1} / 1+\mathrm{s} \mathrm{T}_{\mathrm{JF} 2}$

where, $i$ is 1 and 2 for each frequency band. $\mathrm{J}=\mathrm{L}, \mathrm{I}$ and $\mathrm{h}$

The state-space model of the controller is then:

$\dot{Z}=\mathrm{P} Z+\mathrm{Q} \omega$

$U_{c}=\mathrm{K} R Z$

where: $P, Q, R$ depend on the time constants

$\omega$ is the controller input

$U_{c}$ is the controller output

$\mathrm{K}=\left[\begin{array}{lll}\mathrm{K}_{\mathrm{LF}} & \mathrm{K}_{\mathrm{IF}} & \mathrm{K}_{\mathrm{bF}}\end{array}\right]$

\section{4-2 Equivalent Design Model}

It is difficult to design a controller based on the overall multimachine system model as it involves great numerical difficulties in the design procedures. Morever, this trend is not feasible for practical implementation on a full-scalle power system, as it leads to a centralized control structure in which the controller for a particular generating unit depends not only on measurements of quantities on that unit, but on all other units in the system as well. One approach is to design controllers for each generating unit using a single machine infinite bus representation. This, however, does not take into consederation the dynamic interaction between various units, although it simplefies the design procedures. Alternatively, to facilitate the design procedure an equivalent model approach is developed in [17] to design controllers for conventional generators. The equivalent model for each generator includes the effects of interconnections with other generators in the power sysyem. A similar technique is used in this paper to develop an equivalent model of the SCG. The equivalent model is used to design the flexible controller and the design procedures are described subsequently.

Assuming that the SCG is connected to the ith node, the network voltage components in the common DQ axes, $v_{D Q}^{i}$, at this node is related to the voltage components at the $d-q$ axes of the $S C G$ as

$$
\begin{aligned}
& v_{D Q}^{i}=[T]^{i} v_{d q}^{i}, \\
& T^{i}=\left[\begin{array}{cc}
\cos \delta^{i} & -\sin \delta^{i} \\
\sin \delta^{i} & \cos \delta^{i}
\end{array}\right]
\end{aligned}
$$

The equivalent model approach is based on the fact that voltage variations at distant nodes due to a small change of the SCG input can be neglected. Therefore, perturbing the network voltage equations in the common reference frame yields:

$$
\begin{aligned}
& \Delta v_{D Q}^{i}=\left[Z_{e}^{i}\right] \Delta i_{D Q}^{i} \\
& \text { where } \quad\left[Z_{e}^{i}\right]=\left[\begin{array}{cc}
r_{e}^{i} & -X_{e}^{i} \\
X_{e}^{i} & r_{e}^{i}
\end{array}\right]
\end{aligned}
$$

$Z_{\mathrm{e}}{ }^{\mathrm{i}}$ is the equivalent transmission impedances between node $i$ and all other nodes. The equivalent impedances $Z_{e}^{i}$ can be calculated as follows:

$Z_{\mathrm{e}}^{\mathrm{i}}=\sum_{j=1}^{j=n} z_{i j} \quad, \mathrm{j} \neq \mathrm{i}$

Following the procedure in [17], the open loop equivalent model of the SCG (ith generator) may be written in compact form as:

$$
\begin{aligned}
& X^{i}=A_{e}^{i} X^{i}+B_{e}^{i} U^{i} \\
& \omega^{i}=C_{e}^{i} X^{i} \\
& \text { where, } X^{i} \text { is a state vector } \\
& U^{i} \text { is an input vector }=\left[\begin{array}{ll}
\mathrm{U}_{\mathrm{c}} & \mathrm{U}_{\mathrm{ref}}
\end{array}\right]^{\mathrm{T}} \\
& \mathrm{U}_{\mathrm{c}} \text { is the input from the controller output } \\
& \mathrm{U}_{\mathrm{ref}} \text { is the reference input } \\
& \omega^{i} \text { is the generator speed output }
\end{aligned}
$$

The control problem is to determine a matrix $\mathrm{K}$ so that the output oscillations of the closed loop system will be damped out when a perturbation occurs. Then the closed loop state space equivalent model of the SCG may be written as:

$$
\begin{aligned}
& \dot{\mathrm{X}}_{c}=\mathrm{A}_{c} \mathrm{X}_{c}+\mathrm{B}_{c} U_{r e f} \\
& \omega=C_{c} X_{c} \\
& \mathrm{~A}_{c}=\left[\begin{array}{cc}
\mathrm{A}_{e} & \mathrm{~B}_{e} \mathrm{KR} \\
Q C_{e} & \mathrm{P}
\end{array}\right] ; \mathrm{B}_{c}=\left[\begin{array}{c}
\mathrm{B}_{e} \\
0
\end{array}\right] \text { and } \\
& C_{c}=\left[\begin{array}{ll}
C_{e} & 0
\end{array}\right]
\end{aligned}
$$

The optimization procedure is implemented using the MATLAB package, then values of the controller gains are obtained. The multi-channel controller gains and time constants are given in the Appendix.

\section{5-SIMULATION RESULTS}

To implement this controller, a fairly detailed nonlinear simulation has been built considering all nonlinearities and constraints. Since there is no infinite bus bar in the multi-machine system, the rotor angle and speed deviation for all machines are related to those of machine 1 , which is taken as a reference unit. The effectiveness of the proposed multi-channel controller on the system performance is indicated 


\section{G. A. Morsy, "A Multi-Channel Controller for a SCG in a Multi-Machine System"}

introducing it in the governor loop of the SCG and a detailed digital computer program is used to solve the multi-machine system shown in Fig.1. Simulation results for the system are obtained and studied when subjected to a variety of disturbances such as three phase short circuit at different locations and a step increase of the reference mechanical input of the SCG.

The transient response curves of generators following a $120 \mathrm{~ms}$ duration three-phase short circuit occurring

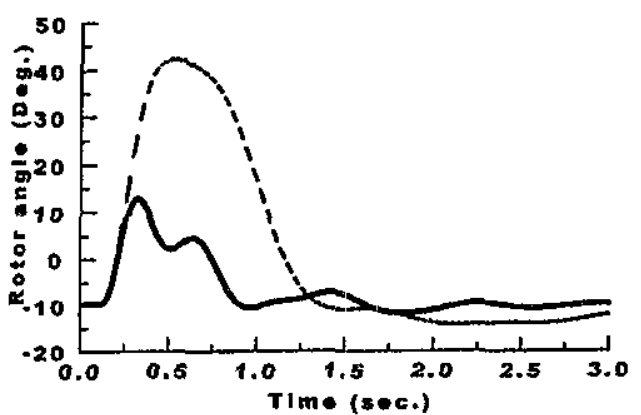

A) Nuclear Unit (G2)
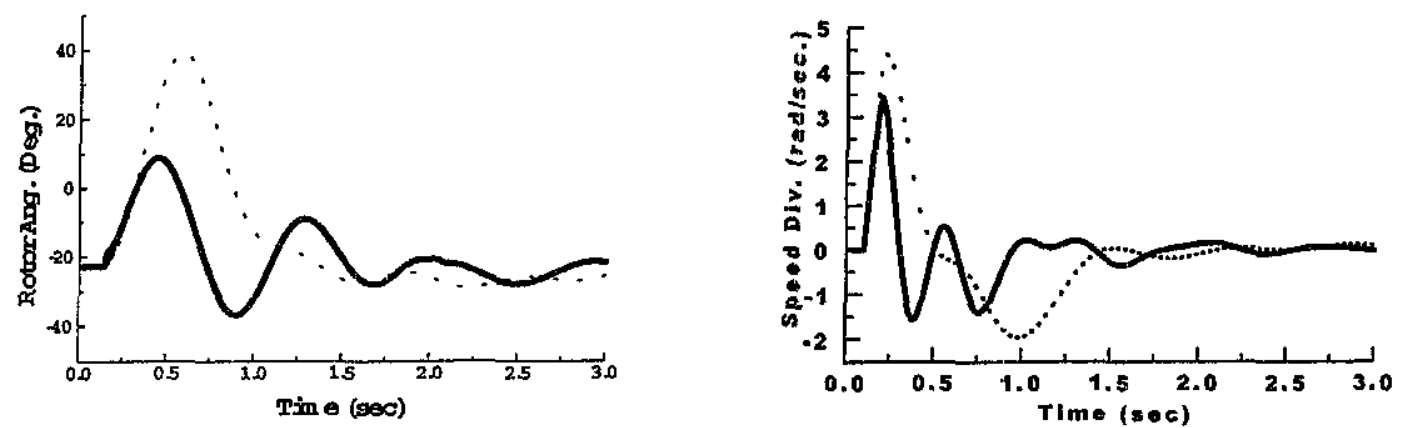

B) Superconducting Unit (G3)
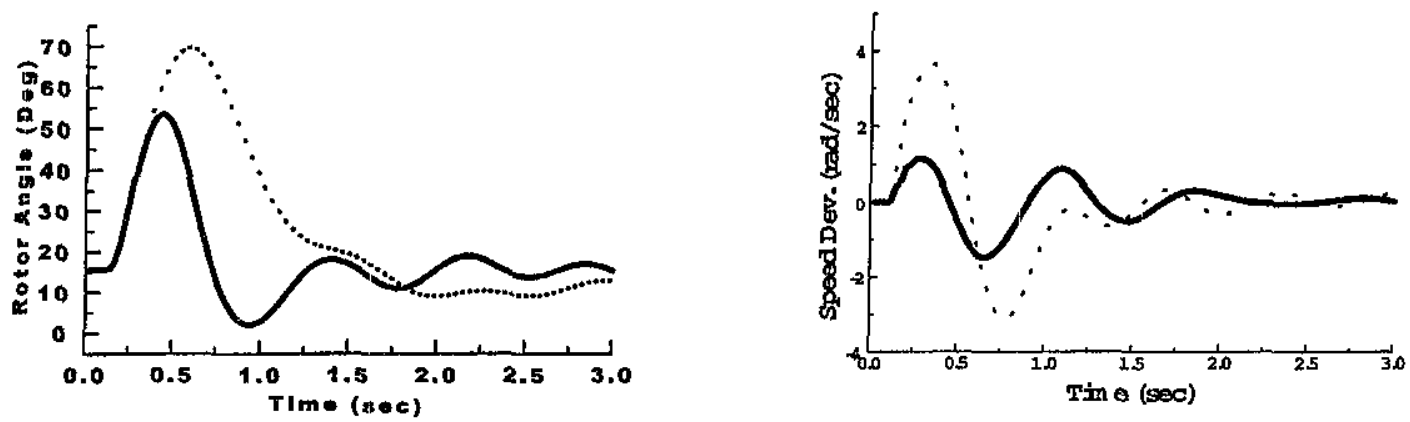

C) Hydro-electric Unit (G4)

Fig. 4- Transient response for three-phase short circuit with $200 \mathrm{~ms}$ duration at bus 5

All conventional units with PSS

$-m$ SCG with phase advance

SCG with multi-channel controller 

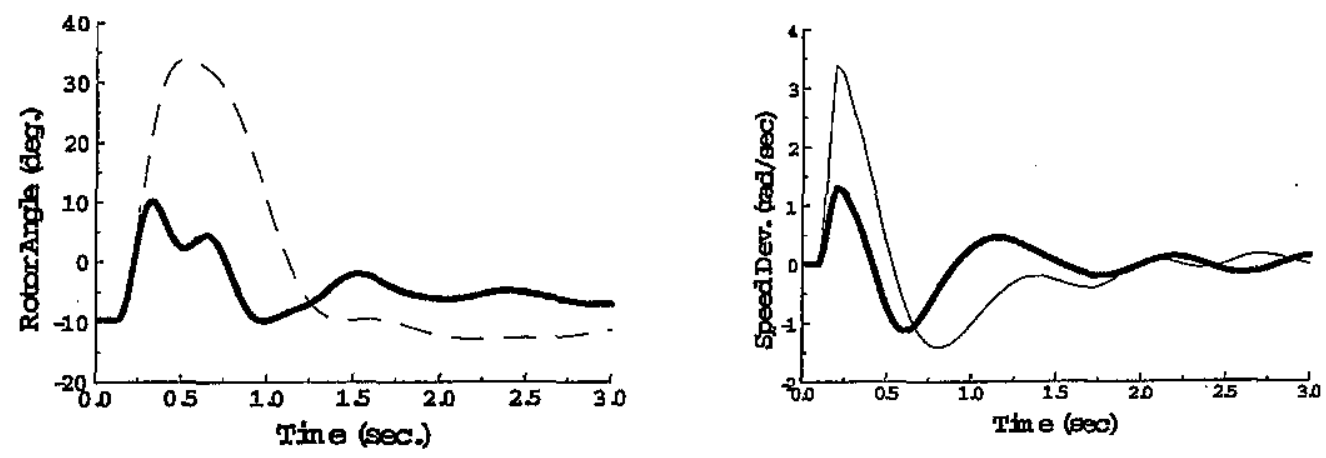

A-Nuclear Unit (G2)
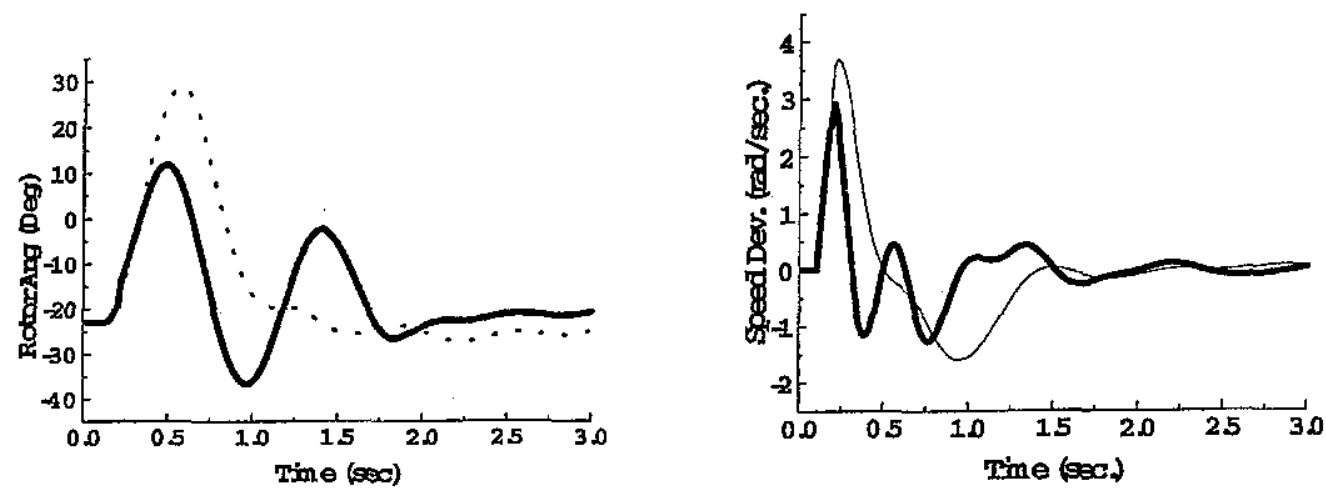

B. Superconducting Unit (G3)
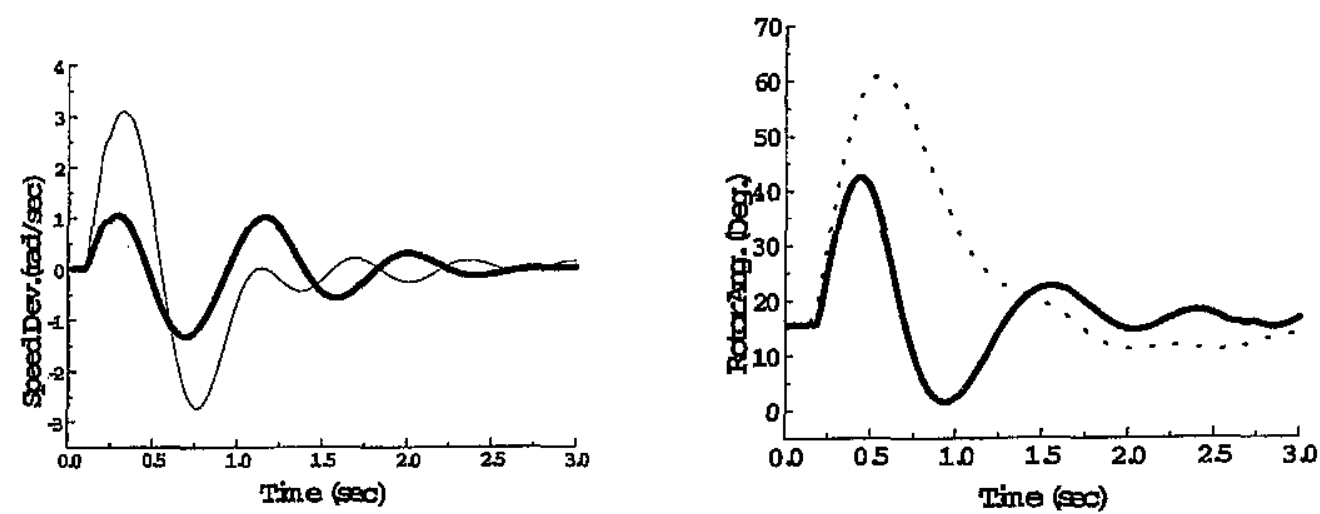

\section{C- Hydro-Electric Unit (G4)}

Fig. 5- Transient response for three-phase short circuit with $200 \mathrm{~ms}$ duration at bus 8 All conventional units with PSS

$m-$ SCG with phase advance

SCG with multi-channel controller

The system also, examined for 0.1 p.u. step increase in the reference mechanical input of the SCG, thus forces the system to a new operating point. Fig.6, shows the system response. It is illustrated that the multi-channel controller achieves, significant improvements in the system behavior, a highly faster damping of oscillations and all system variables quickly reaches their steady state levels. 

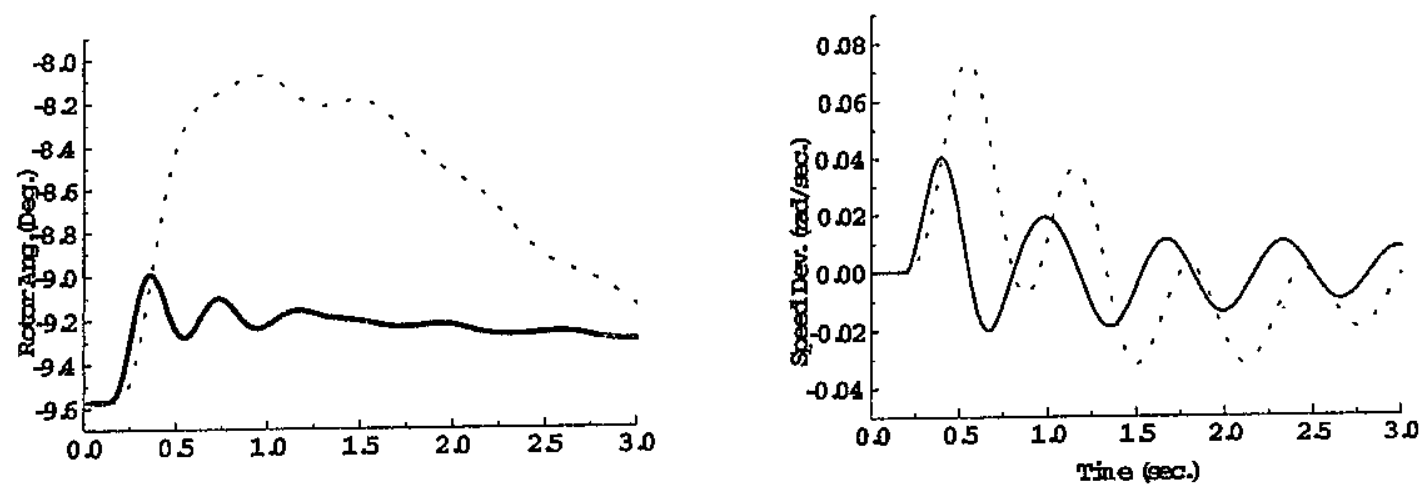

A) nuclear Unit (G2)
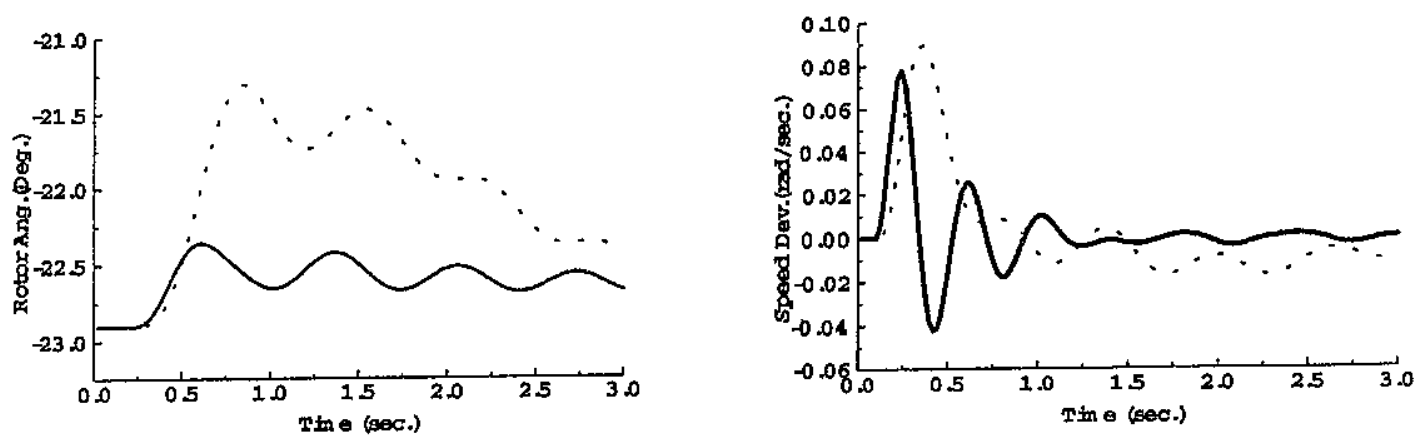

B) Superconducting Unit (G3)
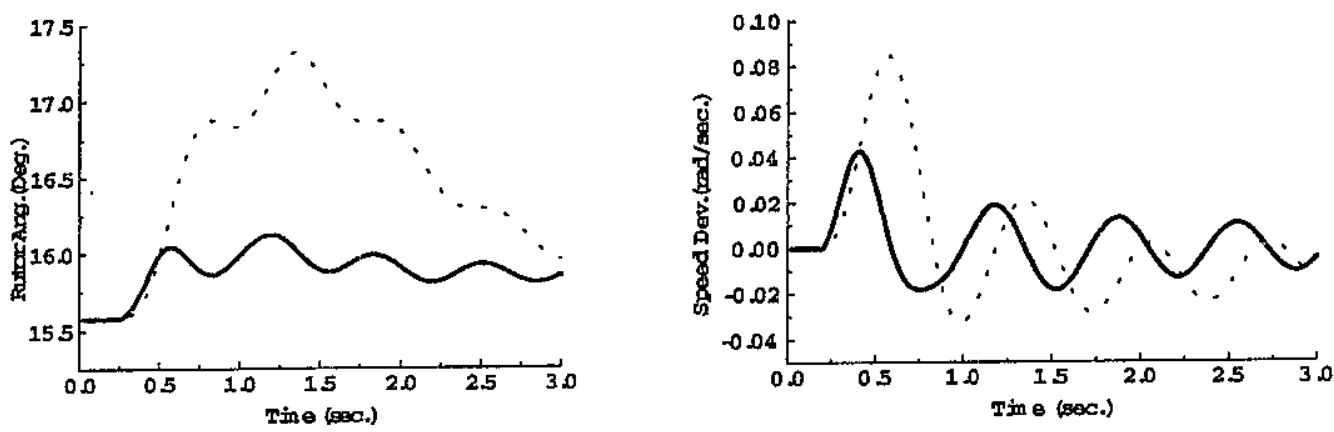

C) Hydro-electric Unit (G4)

Fig. 6- Transient response for $10 \%$ step increase in the reference mechanical input of the superconducting unit All conventional units with PSS

... - - SCG with phase advanc

- SCG with multi-channel controller

\section{6-CONCLUSIONS}

This paper presented procedures for the design of a multi-channel controller for a superconducting generator in a multi-machine power system. The controller is designed based on equivalent model approach. This technique takes into consideration the dynamic interaction between different generating units and facilitates the design procedure. The proposed controller was validated via detailed model 
nonlinear simulation. Simulation results for the system were obtained when superconducting unit equipped with the proposed controller in comparison with others for the superconducting with conventional phase advance network under various disturbances.

The results demonstrate clearly that the proposed controller can improve the multi-machine power system performance as it is capable of providing sufficient damping to system oscillations and variables fast return to steady state levels. The results and techniques presented in the paper are important to power system engineers, forming a useful guide to improve power system performance.

\section{REFERENCES}

[1] G.K. Venayagamerthy and R. G.harley, "A continually online trained neurocontroller for excitation and turbine control of a turbogenerator", IEEE Trans. on Energy Conv., Vol.16, No. 3, Sept.2001, pp. 261-269.

[2] T.Hiyama and Y. Tsutsumi,"Neural network based adaptive fuzzy logic excitation controller", IEEE Trans. on Energy Conv. Vol.15, No. 3, August 2000, pp. 235-240.

[3] A.G. Koronides, G. Kusic, M. Ashkin and C. Flick,"Superconducting generator transient interaction analysis using three dimensional models", IEEE Trans, PAS-100, No. 6,1981.

[4] S.M. Osheba, M.A.A Alyan and Y.H.A. Rahim,"Comparison of transient Performance of superconducting and conventional generators in a multimachine system", IEE Proc., Vol.135, Pt, C, No. 5, Sept. 1988, pp. 389-395.

[5] R.D. Methenson, J. Cherepka and M.L. Patel, "Thermal stress analysis and design of the stator of a 300-MVA superconducting generator", IEEE Trans.on Energy Conv., EC-1, No.3,1986, pp.141-147.

[6] T.S. Kulig, D. Lambercht and M. Liese, "Investigation of the transient performance of superconducting generators with an advanced network torsion-machine program", IEEE Trans. PAS-103, 1984, pp. 1756-1763.

[7] E.V. Larsen and D.A. Swaan, "Applying power system stabilizers: Part 1-3", IEEE Trans. PAS100 No. 8, 1981, pp. 3017-3048.

[8] P.Shamscllahi and O. P. Malik, "Application of neural adaptive power system stabilizer in a multi-machine power system", IEEE Trans. on Enrgy Conv., Vol. 14, No. 3, 1999, pp. 731-736.

[9] G.A.Morsy, A.Kinawy and S.M. Osheba, "Frequency Domain analysis of a Superconducting Generator", Electrical Power System Research (30), 1994,pp.107-113

[10] G.A. Morsy, H. Khattab , A. M. Kinawy, "Design of a PI controller for a superconducting generator", Eng. Research Journal, Vol. 23, No.
1, Fac. of Eng., Minoufiya Univ., Jan 2000, pp. 61-77.

[11] G. A. Morsy, T. A. Mohammed, "An ANN based PI controller for a superconducting generator", Eng. Research Journal, Vol. 24, No. 3, Fac. of Eng., Minoufiya Univ., July 2001, pp.113-125.

[12] R.A.F. Saleh and H.R. Bolton, "Genatic Algorithm-aided Design of a Fuzzy logic Stabilizer for a Superconducting Generator", IEEE Trans. On Power System, Vol. 5, No. 4, 2000, pp. 1329-1335.

[13] G. A. Morsy, H. Yasin and A. A. Khattab, "Robust Controller Design For A Superconducting Generator", MEPCON' 2003, Minoufiya Univ., Shebin El-Kom, Egypt, Dec. 16-18, 2003, Pp. 131-136.

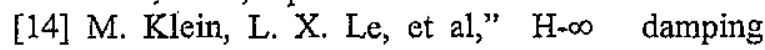
controller design in large power Systems", IEEE Trans., PWRS-10(1), February. 1995, pp. 158166.

[15] I. Kamwa, G. trudle, L. Gurrin-Lajoie, "LowOrder Black Box Models for Control Systems Design in Large Power Systems", Paper presented at PICA'95, Salt Lake, City, May 7-12 1995

[16] J. B. Simo, I. Kamwa, G. Trudel, S. A. Tahan, "Validation of a New Modal Performance Measure for Flexible Controllers Design", IEEE Trans. PWRs-11(2), May 1996, pp. 819-826.

[17] S.M. Osheba and B.W. Hogg, "Equivalent Turbogenerator Model For Design of Multivariable Controllers in Multimachine Systems", Elect. Power \& Energy System, Vol. 6, No.2, April 1984, Pp. 89-100.

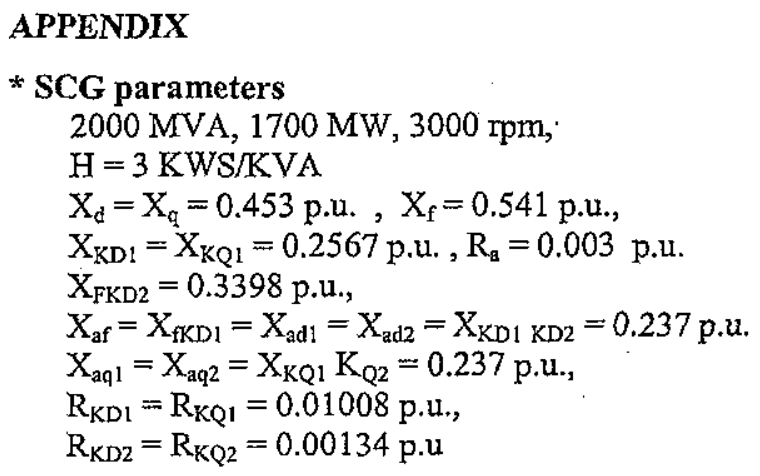


G. A. Morsy, "A Multi-Channel Controller for a SCG in a Multi-Machine System"

* Conventional machines parameters

\begin{tabular}{|l|c|c|l|}
\hline & $\begin{array}{c}\text { Steam } \\
\text { Unit } \\
(\mathrm{Gl})\end{array}$ & $\begin{array}{c}\text { Nuclear } \\
\text { Unit } \\
(\mathrm{G} 2)\end{array}$ & $\begin{array}{c}\text { Hydro-electric } \\
\text { Unit }(\mathrm{G} 4)\end{array}$ \\
\hline $\mathrm{X}_{\mathrm{d}}$ & 2.11 & 2.13 & 0.898 p.u. \\
$\mathrm{X}_{\mathrm{q}}$ & 2.02 & 2.07 & 0,646 p.u. \\
$\mathrm{X}_{\mathrm{ad}}=\mathrm{X}_{\mathrm{af}}$ & 1.955 & 1.88 & 0.658 p.u. \\
$\mathrm{X}_{\mathrm{aq}}$ & 1.865 & 1.82 & 0.406 p.u. \\
$\mathrm{X}_{\mathrm{f}}$ & 2.089 & 2.12 & 0.724 p.u. \\
$\mathrm{X}_{\mathrm{D}}$ & 2.07 & 1.97 & 0.668 p.u. \\
$\mathrm{X}_{\mathrm{Q}}$ & 1.93 & 1.88 & 0.457 p.u \\
$\mathrm{R}_{\mathrm{a}}$ & 0.0046 & 0.0029 & 0.0014 p.u. \\
$\mathrm{R}_{\mathrm{f}}$ & 0.00013 & 0.00092 & 0.00026 p.u \\
$\mathrm{R}_{\mathrm{D}}$ & 0.02 & 0.018 & 0.012 p.u. \\
$\mathrm{R}_{\mathrm{Q}}$ & 0.024 & 0.0212 & 0.02 p.u. \\
$\mathrm{H}$ & 2.32 & 2.52 & $5.15 \mathrm{KW} / \mathrm{KVA}$ \\
\hline
\end{tabular}

* Excitation system parameters

\begin{tabular}{|c|l|c|c|}
\hline Parameter & G1 & G2 & G4 \\
& Thermal & Nuclear & Hydro. \\
\hline $\mathrm{K}_{\mathrm{A}}$ & 200 & 4.0 & 200 \\
$\mathrm{~T}_{\mathrm{A}}(\mathrm{sec})$ & 0.3575 & 0.02 & 0.02 \\
$\mathrm{~K}_{\mathrm{F}}$ & 0.0529 & 0.05 & 0.01 \\
$\mathrm{~T}_{\mathrm{F}}(\mathrm{sec})$ & 1.0 & 0.05 & 1.0 \\
$\mathrm{G}_{\mathrm{S}}$ & 0.03 & 0.03 & 0.04 \\
\hline
\end{tabular}

*Parameters of transmission system

\begin{tabular}{|c|c|c|c|}
\hline Bus No. & $\mathbf{R}_{\mathrm{t}}$ & $\mathbf{X}_{\mathbf{t}}$ & $\mathbf{B}_{\mathrm{t}} / \mathbf{2}$ \\
\hline $1-7$ & 0.0 & 0.12 & 0.0 \\
$7-8$ & 0.009 & 0.15 & 0.07 \\
$8-9$ & 0.009 & 0.1 & 0.098 \\
$2-9$ & 0.0 & 0.12 & 0.0 \\
$9-6$ & 0.009 & 0.15 & 0.07 \\
$6-10$ & 0.009 & 0.15 & 0.07 \\
$3-10$ & 0.0 & 0.12 & 0.0 \\
$10-5$ & 0.009 & 0.1 & 0.07 \\
$5-7$ & 0.009 & 0.15 & 0.07 \\
$5-11$ & 0.009 & 0.15 & 0.07 \\
$11-12$ & 0.018 & 0.3 & 0.035 \\
$11-4$ & 0.0 & 0.12 & 0.0 \\
& & & \\
\hline
\end{tabular}

*Parameters of multi-channel Controller

$$
\begin{aligned}
& \mathrm{T}_{\mathrm{L} 11}=0.5 \mathrm{sec} ., \quad \mathrm{T}_{\mathrm{L} 12}=0.01 \mathrm{sec} \text {, } \\
& \mathrm{T}_{\mathrm{L} 21}=0.01 \mathrm{sec} ., \quad \mathrm{T}_{\mathrm{L} 22}=0.475 \mathrm{sec} \text {, } \\
& \mathrm{T}_{111}=0.4 \mathrm{sec} ., \quad \mathrm{T}_{112}=0.008 \mathrm{sec} \text {, } \\
& \mathrm{T}_{\mathrm{I} 21}=0.008 \mathrm{sec} ., \quad \mathrm{T}_{122}=0.38 \mathrm{sec} \text {, } \\
& \mathrm{T}_{\mathrm{h} 11}=0.2 \mathrm{sec}, \quad \mathrm{T}_{\mathrm{h} 12}=0.004 \mathrm{sec} \text {, } \\
& \mathrm{T}_{\mathrm{h} 21}=0.004 \mathrm{sec}, \quad \mathrm{T}_{\mathrm{h} 22}=0.18 \mathrm{sec} \text {, } \\
& \mathrm{K}_{\mathrm{LF}}=0.5, \quad \mathrm{~K}_{\mathrm{IF}}=0.2 \text {, } \\
& \mathrm{K}_{\mathrm{uF}}=0.1 \quad, \quad \mathrm{~K}_{\mathrm{T}}=1.0 \\
& \mathrm{~T}_{\text {sens }}=0.02 \mathrm{sec} \text {. }
\end{aligned}
$$

\section{* State space equations of turbine and governor} for SCG.

The model of the three-stage steam turbine with reheat and the electro-hydraulic governor considered in this study follows the IEEE standard representation and the special IEEE recommendations for the turbine of the SCG. Their state equations may be written as:

$$
\begin{aligned}
& p Y_{H P}=\left(\begin{array}{ll}
G_{M} P_{o} & Y_{H P}
\end{array}\right) / T_{H P} \\
& p Y_{R P}=\left(\begin{array}{ll}
Y_{H P} & Y_{R H}
\end{array}\right) / T_{R H} \\
& p Y_{I P}=\left(\begin{array}{ll}
G_{I} Y_{R H} & Y_{I P}
\end{array}\right) T_{I P} \\
& p Y_{L P}=\left(\begin{array}{ll}
G_{I P} & Y_{L P}
\end{array}\right) / T_{L P} \\
& T_{m}=F_{H P} Y_{H P}+F_{l P} Y_{l P}+F_{L P} Y_{L P}
\end{aligned}
$$

The electro-hydraulic governor equations are :

$$
\begin{aligned}
& p G_{M}=\left(\begin{array}{ll}
U_{G M} & G_{M}
\end{array}\right) \pi_{G M} \\
& p G_{I}=\left(\begin{array}{ll}
U_{G I} & G_{I}
\end{array}\right) / T_{G I}
\end{aligned}
$$

Where the position and rate limits are,

$$
\begin{gathered}
0 \leq G_{M,} G_{I} \leq 1.0 \\
\text { and }-6.7 \leq p G_{M}, p G_{1} \leq 6
\end{gathered}
$$

* Parameters of Governor and Turbine for SCG

$$
\begin{array}{ll}
\mathrm{T}_{\mathrm{HP}}=0.1 \mathrm{sec} ., & \mathrm{F}_{\mathrm{HP}}=0.26 \text { p.u, } \\
\mathrm{T}_{\mathrm{IP}}=0.3 \mathrm{sec} ., & \mathrm{F}_{\mathrm{IIP}}=0.42 \text { p.u. } \\
\mathrm{T}_{\mathrm{LP}}=0.3 \mathrm{sec} ., & \mathrm{F}_{\mathrm{L} . \mathrm{P}}=0.32 \text { p.u. } \\
\mathrm{T}_{\mathrm{RH}}=10 \mathrm{sec} ., & \mathrm{T}_{\mathrm{GM}}=\mathrm{T}_{\mathrm{G} . \mathrm{I}}=0.1 \mathrm{sec} . \\
\mathrm{P}_{\mathrm{o}}=1.2 \text { p.u. } &
\end{array}
$$

